- By March, the JGI should have sequenced the fish's genome at least three times over, covering $95 \%$ of the genome. This should provide enough data to assemble the fragments into contiguous stretches of DNA, and allow comparisons with the mouse and human genomes.

"I want to take it higher," says Hawkins. Higher coverage, perhaps to four or five times, would result in longer stretches of unbroken DNA, and therefore better comparisons.

Other members of the consortium include Singapore's Institute of Molecular and Cell Biology (IMCB), the US Institute of Systems Biology in Seattle, the UK Human Genome Mapping Project Resource Centre, and the US Molecular Sciences Institute in Berkeley, California. They will share the computational load and be responsible for 'finishing' the Fugu genome by putting together the fragments produced by the JGI's shotgun technique. The finishing phase is expected to be complete by the spring of 2002 .

The Fugu genome is thought to have about the same number of genes as the human genome $-60,000$ to 65,000 , according to estimates by IMCB's B. Venkatesh. But the Fugu genes are spread over only 400 million DNA base pairs, compared with some 3 billion base pairs in the human and mouse. "It can be thought of as the minimum set of genes to build a vertebrate," says Venkatesh.

Comparing Fugu and human "is a very cheap way to get a gene catalogue", says Jean Weissenbach, director of the Centre National de Séquençage in Evry, France. This spring, Weissenbach used the partial sequence of a related puffer fish, Tetraodon nigroviridis, to predict that the human genome has $28,000-34,000$ genes. He expects the Fugu sequence to confirm that estimate.

And because that genome contains few repeats or 'junk' DNA, it should be easier to find similar sequences - and hence genes - between Fugu and human. Human, mouse and Fugu genes all share exons - lengths of DNA that code for proteins. But in the two mammalian genomes, some introns stretches of DNA that are not translated into the final protein - also come as part of the package. Having Fugu's sequence will help weed out those noncoding areas, says Weissenbach.

For IMCB's Chris Tan the project is both a way for Singapore to develop in bioinformatics and biocomputation and a way to move genomics beyond sequencing to "really exciting applications and functional analysis". http://jgi.doe.gov/tempweb/programs/fugu.htm

\title{
US fusion community 'must end isolation', says panel
}

\section{Colin Macilwain, Washington}

The quality of fusion research in the United States is on a par with other areas of the physical sciences, according to an assessment by the National Academy of Sciences. But the fusion community is isolated from other scientists, struggles to attract young talent, and tends to put the pursuit of fusion energy ahead of the pursuit of good science, the academy warns.

The assessment, undertaken by a panel chaired by Charles Kennel, director of the Scripps Institution of Oceanography in La Jolla, California, recommends that fusion scientists make "a systematic effort to reduce [their] scientific isolation".

It also calls on the National Science Foundation to increase its involvement in fusion research - most US magnetic-fusion work is supported by a \$250-million-a-year programme at the Department of Energy (DoE).

DoE officials welcomed the report's endorsement of the quality of science in their programme. But fusion scientists - many of them gathered in Québec City in Canada last week for the American Physical Society's plasma-physics meeting — were taken aback by the harshness of the panel's judgement on the discipline, which it branded as "intellectually isolated from the rest of science".

"Most scientists funded by the program do not, in general, actively participate in the wider scientific culture," says the executive summary of the panel's report. "As a result, the flow of scientific information both out of and into the field has stagnated."

But in its main finding, the panel said that the general quality of science funded by the DoE magnetic-fusion programme was "easily on a par with other leading areas of contemporary physical science".

Four years ago the fusion programme lost

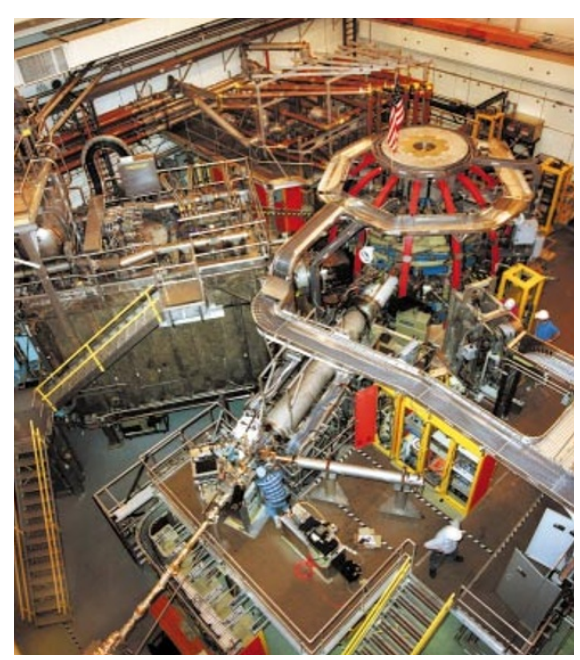

Nice work: the report praised fusion research, such as the National Spherical Torus Experiment.

one-third of its budget and the DoE changed its main goal from developing fusion-based energy sources to improving the scientific understanding of fusion. But according to Kennel, programme resources are still allocated largely to approaches that demonstrate progress towards fusion power.

Some fusion scientists argue that their experiments need to be relevant to fusion power. Magnetic fusion "is a mission-orientated science”, says David Baldwin, senior vice-president of the fusion group at General Atomics in San Diego, California.

But others welcomed the report's call for more emphasis on scientific questions. Bill Dorland, a theorist at the University of Maryland's Institute for Plasma Research, says time on large fusion facilities tends to go to experiments that promise to raise technical performance, rather than understand why performance is restricted.

\section{Whitehead enters into array deal}

Steve Nadis, Boston

The high-tech manufacturers Corning have entered into a \$10 million research partnership with the Whitehead Institute for Biomedical Research at the Massachusetts Institute of Technology. Corning will give the Whitehead \$2.5 million for each of the next four years for the development of what the company calls "the next generation of DNA microarrays and other tools of the post-genome world".

The partnership aims to produce DNA chips that can analyse 10,000 human genes at a time and to develop protein arrays to facilitate the simultaneous study of thousands of proteins.

"There is a critical need for researchers in academia and industry to collaborate in the battle against human disease in order to develop technologies with the potential to revolutionize medical science," says Richard Young, a biologist at the Whitehead and MIT who will direct the project. "We intend to use technologies developed through the joint initiative with Corning to lay a foundation for better drugs and vaccines." 